\title{
Investigation on the Motor Recovery Effect of a Self-Assembling Nonofiber in the Spinal Cord Injury
}

\section{Model in Rat}

Shima Tavakol ${ }^{1,2,3}$, Hadi Aligholi ${ }^{1}$, Arezou Eshaghabadi ${ }^{1}$, Sayed Mostafa Modarres Mousavi ${ }^{1}$, Jafar Ai ${ }^{4}$, Seyed Mehdi

$$
\text { Rezayat }^{2^{*}}
$$

${ }^{1}$ Shefa Neuroscience Research Center, Khatam Alanbia Hospital, Tehran, Iran.

${ }^{2}$ Department of Medical Nanotechnology, School of Advanced Technologies in Medicine, Tehran University of Medical Sciences, Tehran, Iran. ${ }^{3}$ Student's Scientific Research Center, Tehran University of Medical Sciences, Tehran, Iran.

${ }^{4}$ Department of Tissue Engineering, School of Advanced Technologies in Medicine, Tehran University of Medical Sciences, Tehran, Iran.

\section{A BSTRACT}

Introduction: Spinal cord injury (SCI) is a serious disabling condition associated with paralysis. Owing to suitable effects of hydrogels compared to preformed scaffolds, in this study a hydrogel based biomaterial, Matrigel, was applied. Matrigel is a termogel that forms nanofibers and hydrogel above $20^{\circ} \mathrm{C}$. It contains laminin, nidogen and some growth factors that induce neural differentiation. Materials and Methods: A moderate spinal cord contusion was performed in adult rats and 10 days after injury, matrigel was implanted. Then, they follow up via Basso, Beattie, Bresnahan test for 42 days. Cresyl violet staining was performed as a histopatological analysis. Results: Our data indicated less inflammation and dark cells in Matrigel group compared to control group. Locomotor test showed significant improvement of motor recovery in Matrigel group. Conclusion: Our results suggest that Matrigel via some growth factors and adhesive molecules may have beneficial effects on functional recovery in SCI.

* Corresponding Author: Seyed Mehdi Rezayat

E-mail:Rezayat@tums.ac.ir 


\title{
بررسى اثر بهبود حر كتى نانوفيبر خود سامانده در مدل ضايعة نخاعى در موش صحرايى
}

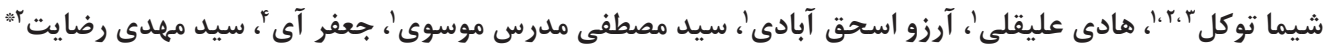 \\ "مركز تحقيقات علوم اعصاب شفا، بيمارستان خاتم الانبياء، تهران، ايران.

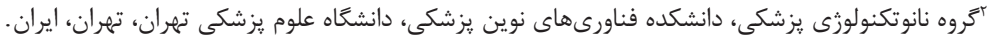

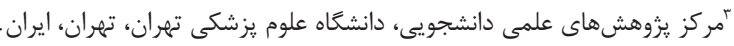

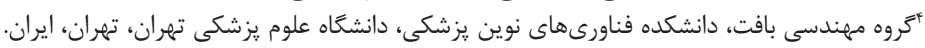

كليد وازهها:

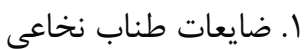

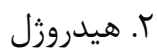

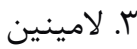

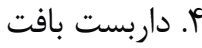

مقدمه: صدمهُ نخاعى يك وضعيت ناتوان كننده خطرناك است كه ميىتواند منجر به فلج شدن گرددد. به

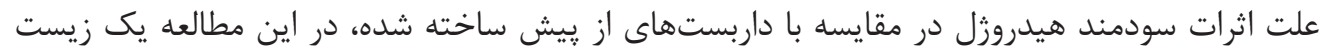

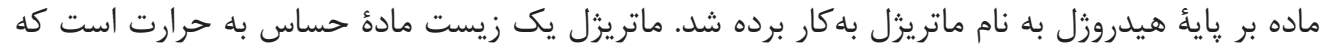

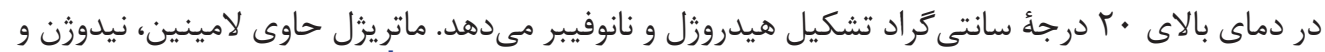

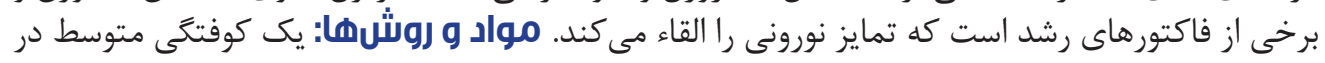

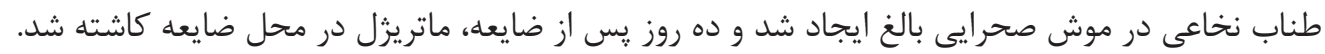

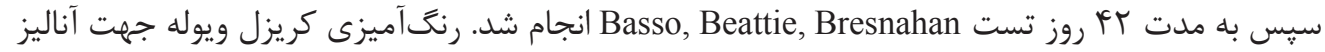

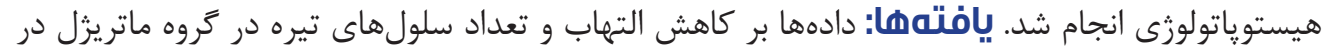

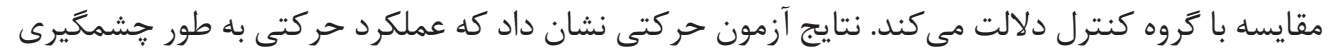

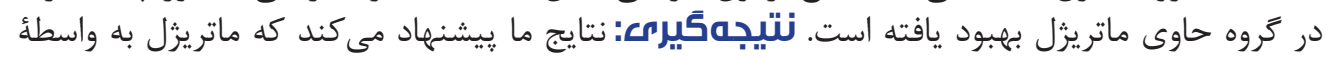

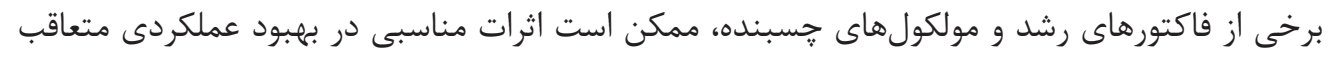
ضايعة نخاعى داشته باشد.

$$
\text { "نويسنده مسئول: سيد مهدى رضايت }
$$

آدرس الكترونيكى: Rezayat@tums.ac.ir 


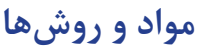

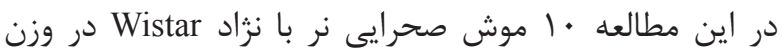

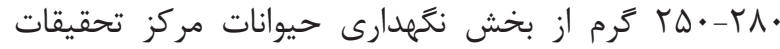

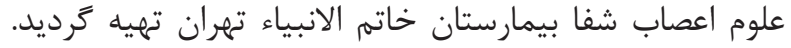

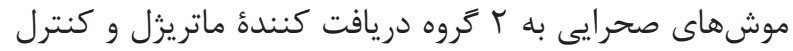

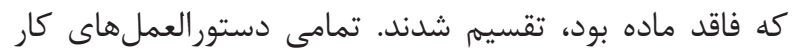

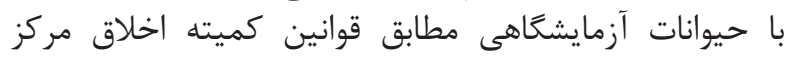
تحقيقات علوم اعصاب شفا انجام شد.

براى ايجاد ضايعأ نخاعى يك صدمه با مدل كوفتكى به وسيله

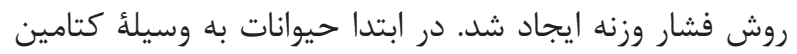

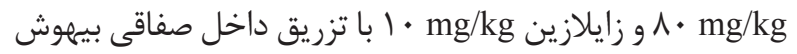

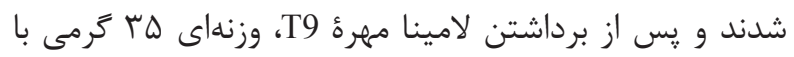

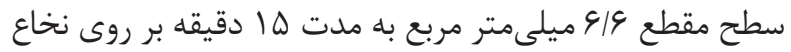

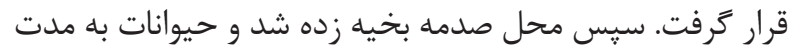

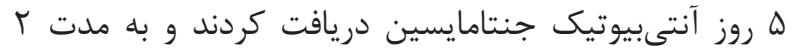

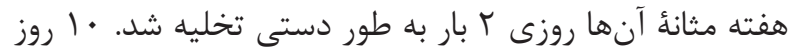

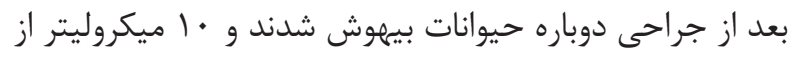

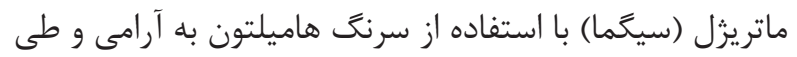
•ا لا دقيقه در محل ضايعه تزريق كرديد.

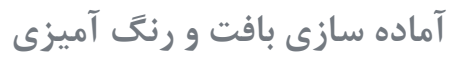

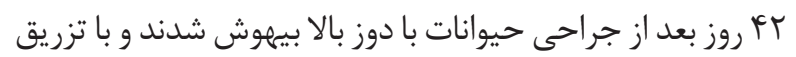

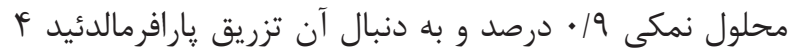

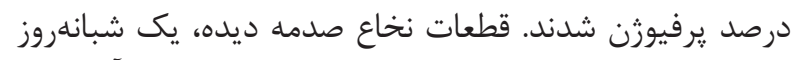

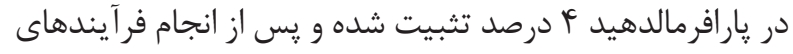

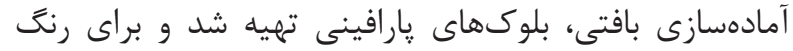
آميزى كريزل ويوله مورد استفاده قرار كرفت بارئ

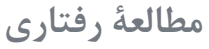

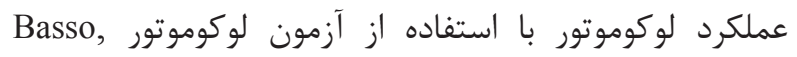
Beattie, Bresnahan (BBB)

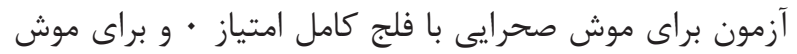
صحرايى طبيعى امتياز آ ثبت شدراب فائ كامل

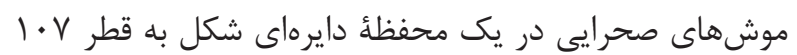

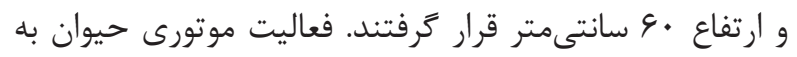

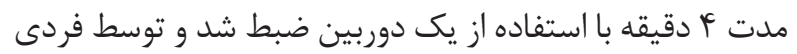

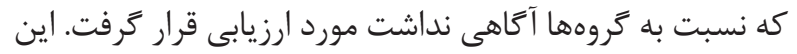

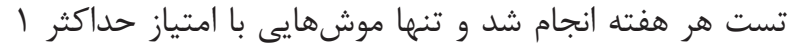

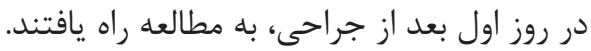

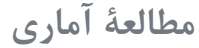

از نرم افزار Graph pad و آزمون آمارى t- student براى آناليز آمارى اين مطالعه استفاده شد.

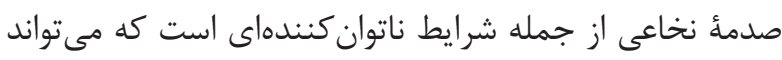

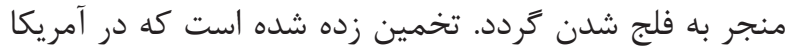

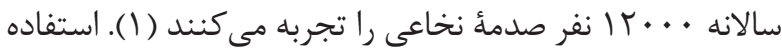

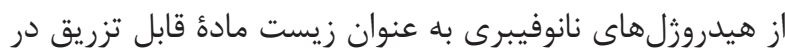

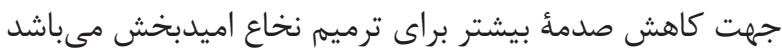

مطالعات نشان داده است كه قطر نانوفيبر، تمايز و تكثير به

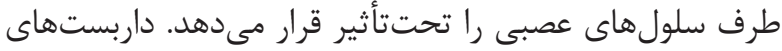

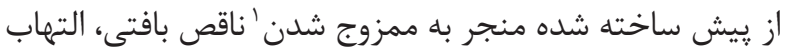

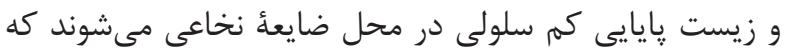

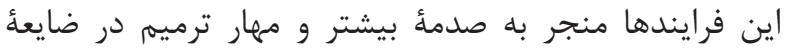

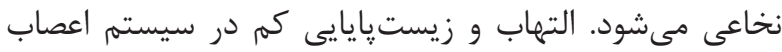

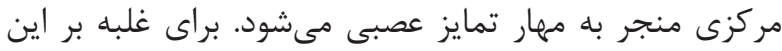

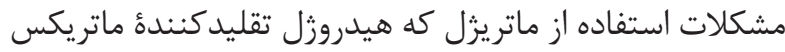

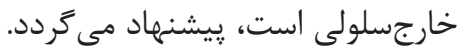

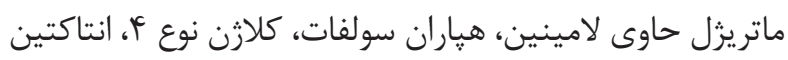

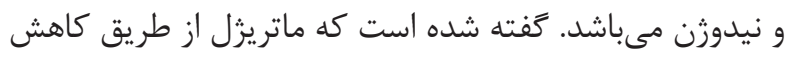

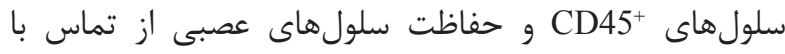

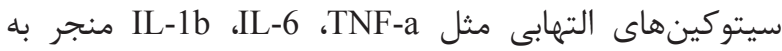

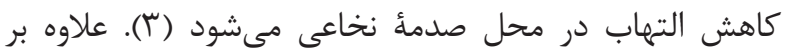

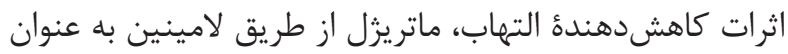

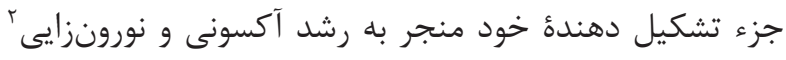

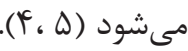

קندين روش براى ساخت نانوفيبر وجود دارد كه خودساماندهى"

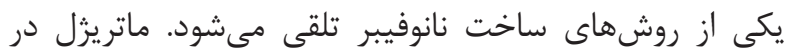

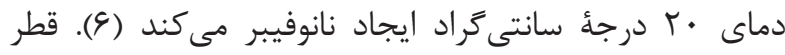

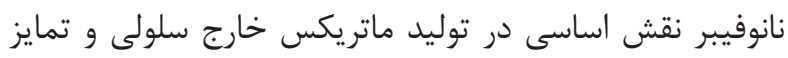

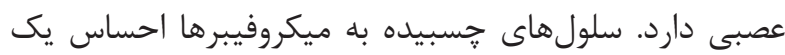

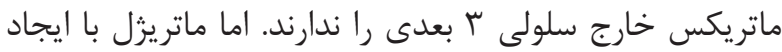

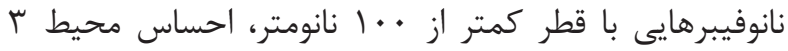

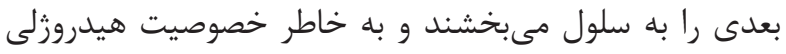

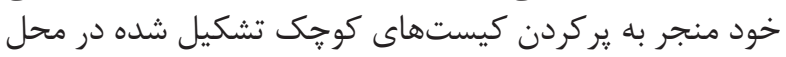

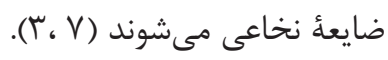

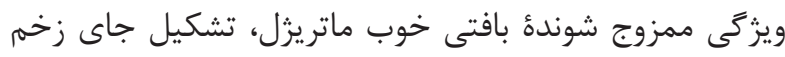

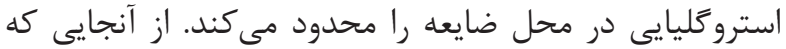

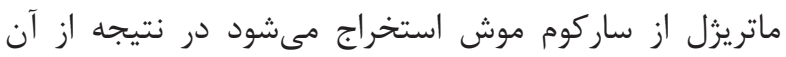

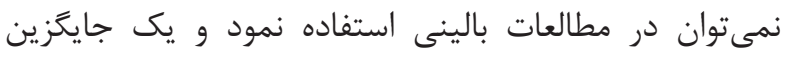

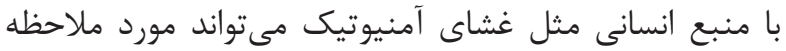

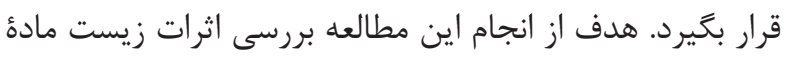

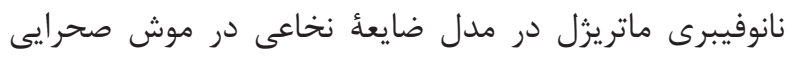
مىباشد. 


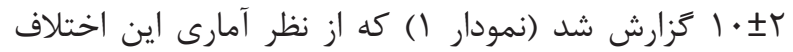

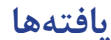

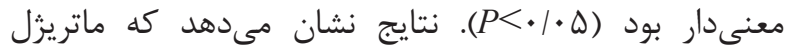

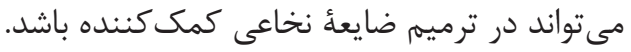

$$
\text { بحث و نتيجه كيرى }
$$

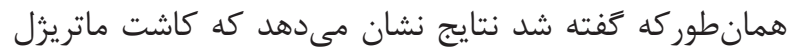

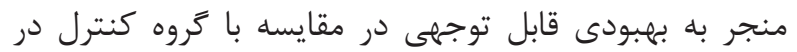

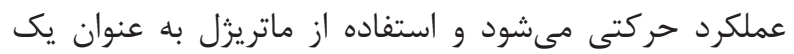

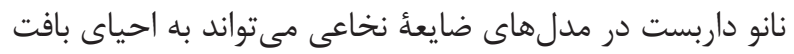

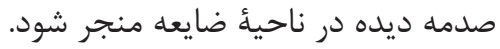
مقياس عملكردى سيستم اعصاب مركزى در طيف نانو و و ميكرو

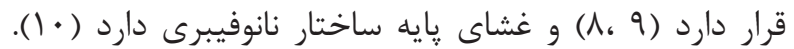

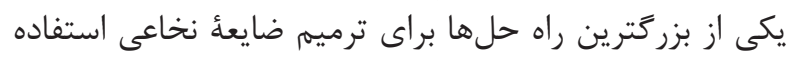

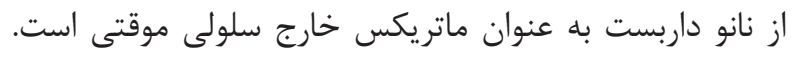

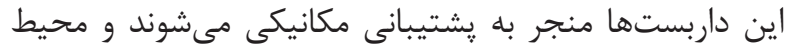

مناسبى را براى تكثير و تمايز سلول عصبى ايجاد مئى كنند.

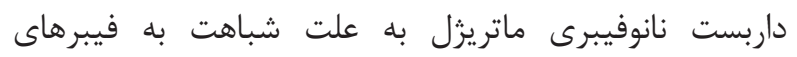

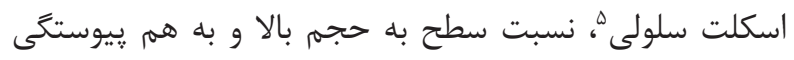

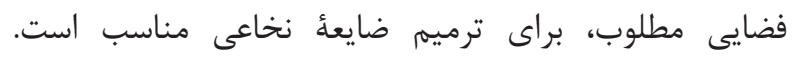
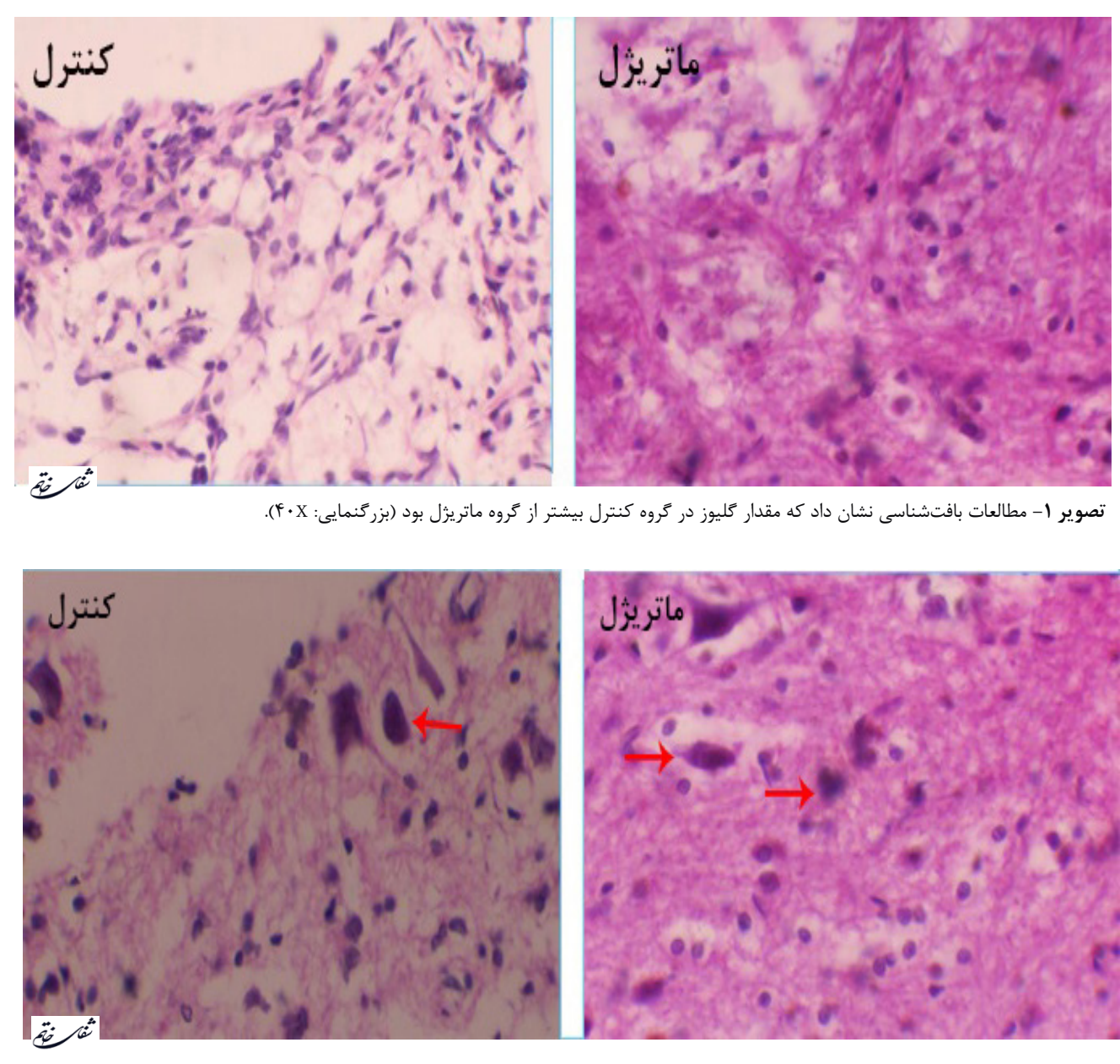

تصوير Y- مطالعات بافتشناسى نشان داد كه تعداد سلول هاى تيره در كروه كنترل بيشتر از كروه ماتريزل بود (بزركنمايى: •X).

\footnotetext{
${ }^{4}$ Morphology

${ }^{5}$ Cytoskeleton
}

در اين مطالعه از مدل كوفتتى براى ايجاد ضايعأ نخاعى استفاده

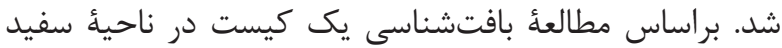

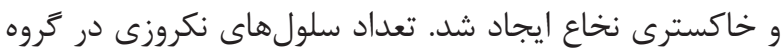

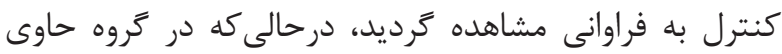

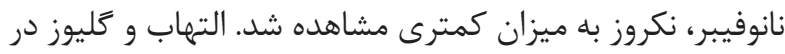

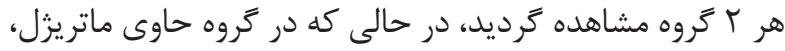

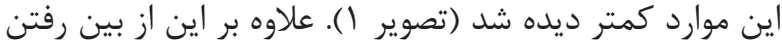

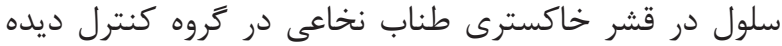

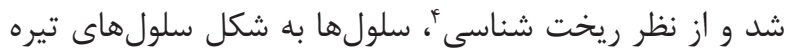

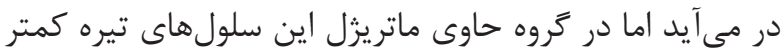

ديده مىشد (تصوير r).

نتايج مطالعُ رفتارى

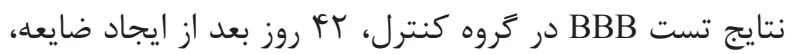

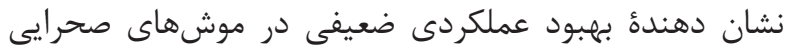

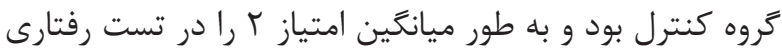

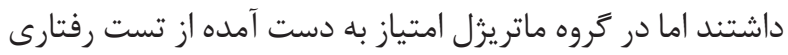




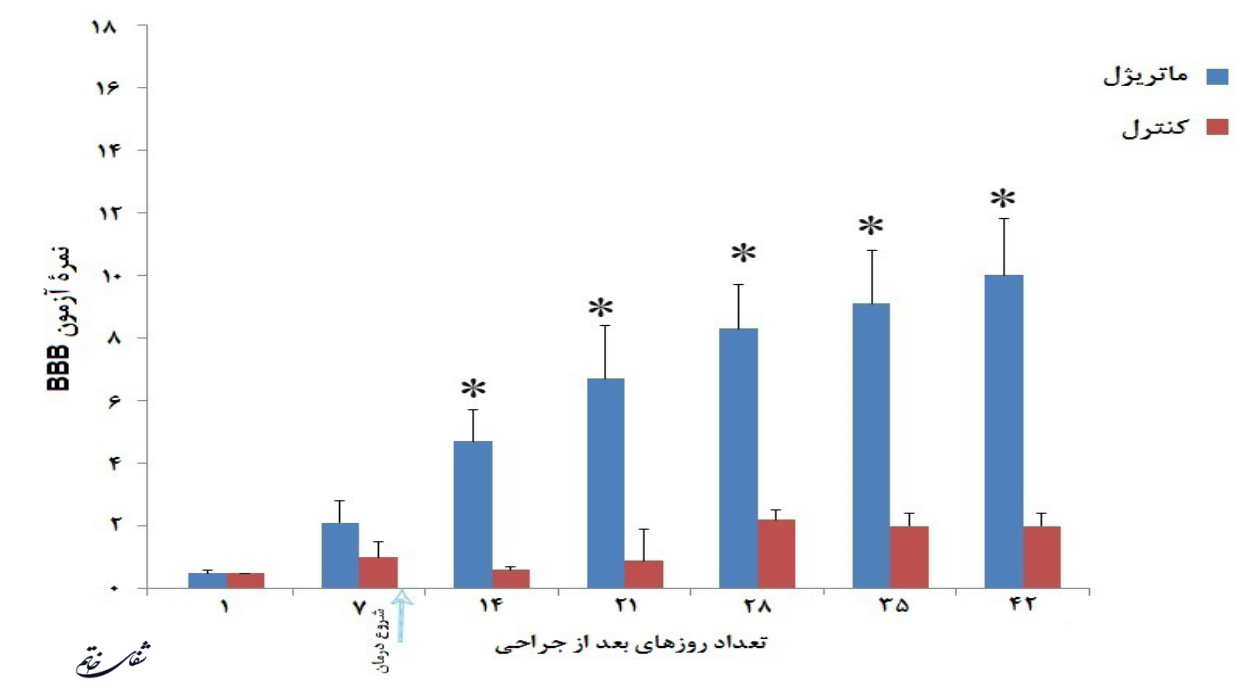

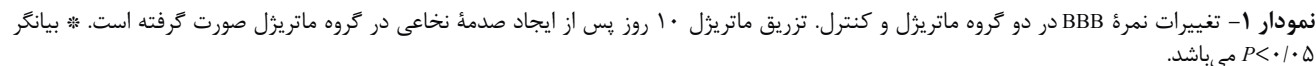

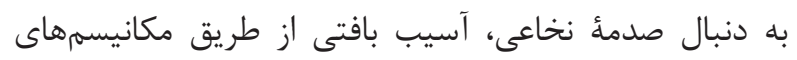

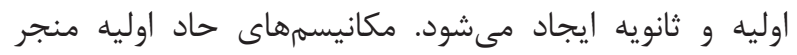

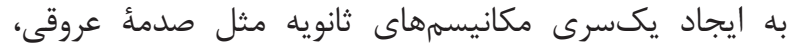

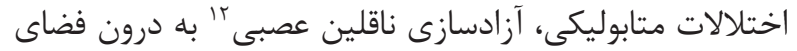

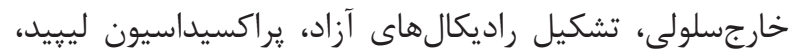

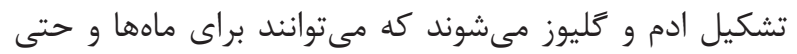
سالها بعد از صدمأ نخاعى باقى بمانند (1) (1).

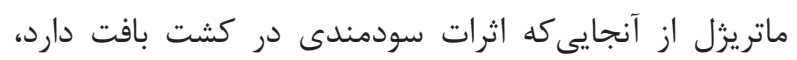

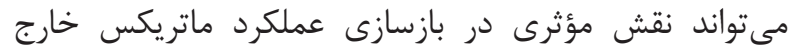

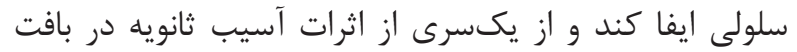

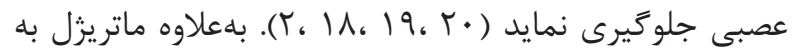

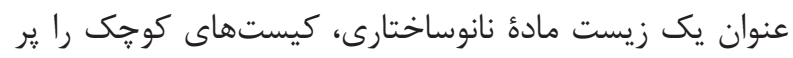

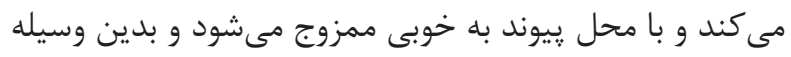

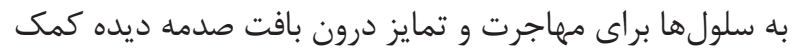

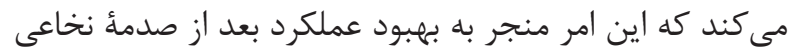
مىشود.

${ }^{6}$ Fibroblast growth factor 2

${ }^{7}$ Epidermal growth factor

${ }^{8}$ Insulin-like growth factor 1

${ }^{9}$ Platelet-derived growth factor

${ }^{10}$ Nerve growth factor

${ }^{11}$ Transforming growth factor beta

${ }^{12}$ Neurotransmitters

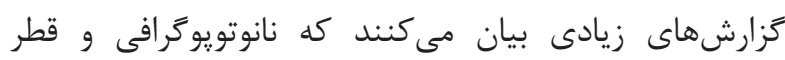

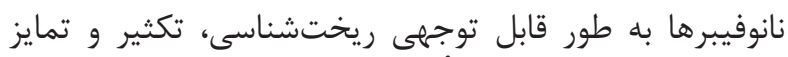

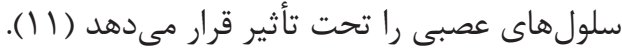
Christopherson قطر فيبر از طريق كاهش تشكيل فيبرهاى اكتين و توسعان

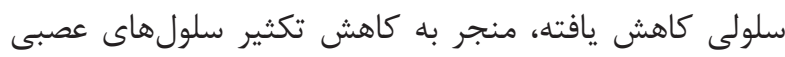

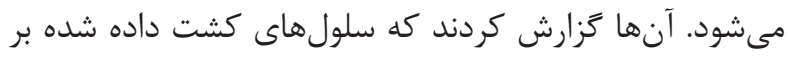

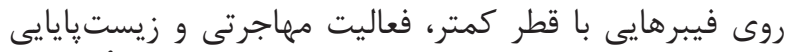

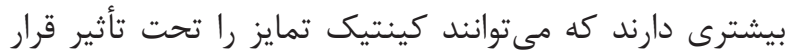

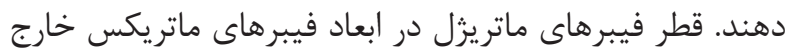

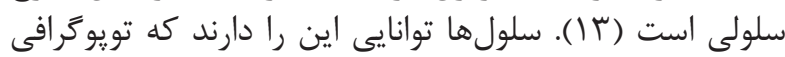

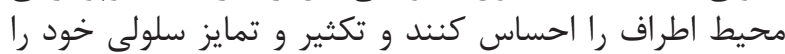
تغيير دهند (If). (I)

علاوه بر ساختار، ماتريزل حاوى لامينين، هياران سولفات و مواد

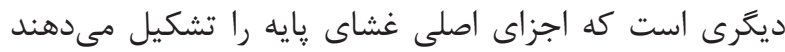

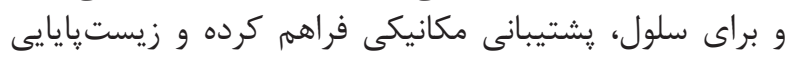

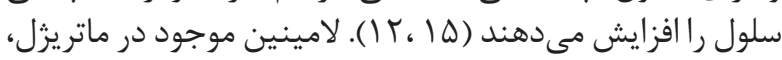

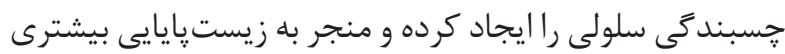

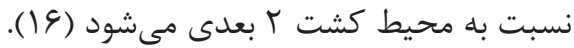

مطالعات نشان داده است كه ماتريزل غنى از لامينين منجر

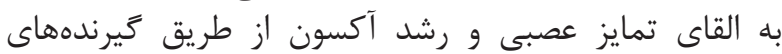

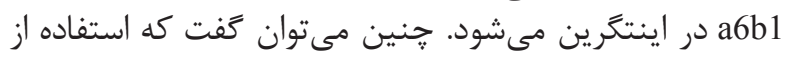

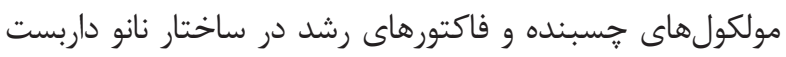

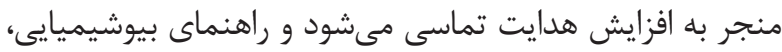

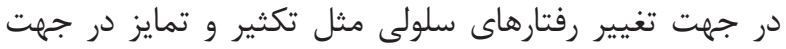

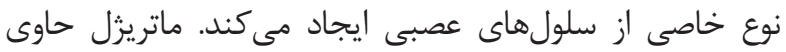

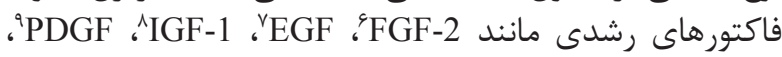

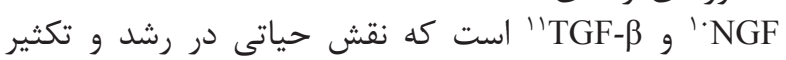

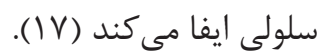


1. Macaya D, Spector M. Injectable hydrogel materials for spinal cord regeneration: a review. Biomed Mater. 2012; 7(1): 012001.

2. Tavakol S, Modarres Mousavi SM, Masummi M, Amani A, Rezayat SM, Ai J. The effect of Noggin supplementation in Matrigel nanofiber-based cell culture system for derivation of neural-like cells from human endometrial-derived stromal cells. J Biomed Mater Res A. 2014; doi: 10.1002 /jbm.a.35079.

3. Uemura M, Refaat MM, Shinoyama M, Hayashi H, Hashimoto N, Takahashi J. Matrigel supports survival and neuronal differentiation of grafted embryonic stem cell-derived neural precursor cells. J Neurosci Res. 2010; 88(3): 542-51.

4. Kerever A, Schnack J, Vellinga D, Ichikawa N, Moon C, Arikawa-Hirasawa E, et al. Novel extracellular matrix structures in the neural stem cell niche capture the neurogenic factor fibroblast growth factor 2 from the extracellular milieu. Stem cells. 2007; 25(9): 2146-57.

5. Hubert T, Grimal S, Carroll P, Fichard-Carroll A. Collagens in the developing and diseased nervous system. Cell Mol Life Sci. 2009; 66(7): 1223-38.

6. GelainF, Bottai D, Vescovi A, Zhang S. Designer selfassembling peptide nanofiber scaffolds for adult mouse neural stem cell 3-dimensional cultures. PLoS One. 2006; 1(1): e119.

7. Massumi M, Abasi M, Babaloo H, Terraf P, Safi M, Saeed M, et al. The effect of topography on differentiation fates of matrigel-coated mouse embryonic stem cells cultured on PLGA nanofibrous scaffolds. Tissue Eng Part A. 2011; 18(5-6): 609-20.

8. Silva GA. The nanostructure of the nervous system and the impact of nanotechnology on neuroscience. Biotechnology. 2006; 11: 1-12.

9. Silva GA. Small neuroscience: the nanostructure of the central nervous system and emerging nanotechnology applications. Curr Nanosci. 2005; 1(3): 225-36.

10. Birk DE, Trelstad RL. Extracellular compartments in matrix morphogenesis: collagen fibril, bundle, and lamellar formation by corneal fibroblasts. J Cell Biol. 1984; 99(6): 2024-33.

11. Bozkurt A, Deumens R, Beckmann C, Olde Damink
L, Schügner F, Heschel I, et al. In vitro cell alignment obtained with a Schwann cell enriched microstructured nerve guide with longitudinal guidance channels. Biomaterials. 2009; 30(2): 169-79.

12. Christopherson GT, Song H, Mao HQ. The influence of fiber diameter of electrospun substrates on neural stem cell differentiation and proliferation. Biomaterials. 2009; 30(4): 556-64.

13. Mahairaki V, Lim SH, Christopherson GT, Xu L, Nasonkin I, Yu C, et al. Nanofiber matrices promote the neuronal differentiation of human embryonic stem cellderived neural precursors in vitro. Tissue Eng Part A. 2010; 17(5-6): 855-63.

14. LaPlaca MC, Prado GR, Cullen D, Simon CM. Plasma membrane damage as a marker of neuronal injury. Conf Proc IEEE Eng Med Biol Soc. 2009; 2009: 1113-6.

15. Paulsson M. Basement membrane proteins: structure, assembly, and cellular interactions. Crit Rev Biochem Mol Biol. 1992; 27(1-2): 93-127.

16. Koh H, Yong T, Chan CK, Ramakrishna S. Enhancement of neurite outgrowth using nanostructured scaffolds coupled with laminin. Biomaterials. 2008; 29(26): 3574-82.

17. Ma W, Tavakoli T, Derby E, Serebryakova Y, Rao MS, Mattson MP. Cell-extracellular matrix interactions regulate neural differentiation of human embryonic stem cells. BMC Dev Biol. 2008; 8: 90.

18. Novikova LN, Mosahebi A, Wiberg M, Terenghi G, Kellerth JO, Novikov LN. Alginate hydrogel and matrigel as potential cell carriers for neurotransplantation. J Biomed Mater Res A. 2006; 77(2): 242-52.

19. Cooke MJ, Vulic K, Shoichet MS. Design of biomaterials to enhance stem cell survival when transplanted into the damaged central nervous system. Soft Matter. 2010; 6(20): 4988-98.

20. Tavakol S, Aligholi H, Gorji A, Eshaghabadi A, Hoveizi E, Tavakol B, et al. Thermogel nanofiber induces human endometrial-derived stromal cells to neural differentiation: In vitro and in vivo studies in rat. J Biomed Mater Res A. 2014; doi: 10.1002/ jbm.a.35117. 